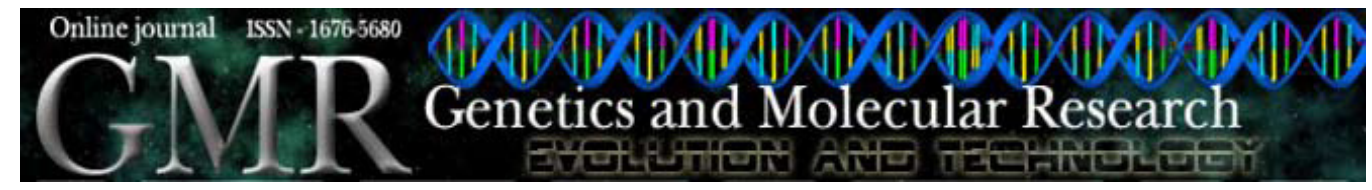

\title{
Pollination of tomatoes by the stingless bee Melipona quadrifasciata and the honey bee Apis mellifera (Hymenoptera, Apidae)
}

\author{
S.A. Bispo dos Santos, A.C. Roselino, M. Hrncir and L.R. Bego \\ Departamento de Biologia, Faculdade de Filosofia, \\ Ciências e Letras de Ribeirão Preto, \\ Universidade de São Paulo, Ribeirão Preto, SP, Brasil \\ Corresponding author: S.A. Bispo dos Santos \\ E-mail: sbispo@usp.br
}

Genet. Mol. Res. 8 (2): 751-757 (2009)

Received December 12, 2008

Accepted January 26, 2009

Published June 30, 2009

\begin{abstract}
The pollination effectiveness of the stingless bee Melipona quadrifasciata and the honey bee Apis mellifera was tested in tomato plots. The experiment was conducted in four greenhouses as well as in an external open plot in Ribeirão Preto, SP, Brazil. The tomato plants were exposed to visits by $M$. quadrifasciata in one greenhouse and to A. mellifera in another; two greenhouses were maintained without bees (controls) and an open field plot was exposed to pollinators in an area where both honey bee and stingless bee colonies are abundant. We counted the number of tomatoes produced in each plot. Two hundred tomatoes from each plot were weighed, their vertical and transversal circumferences were measured, and the seeds were counted. We collected 253 Chrysomelidae, 17 Halictidae, one Paratrigona sp, and one honey bee from the flowers of the tomato plants in the open area. The largest number of fruits (1414 tomatoes), the heaviest and largest tomatoes, and the ones with the most seed were collected from the greenhouse with stingless bees. Fruits cultivated in the greenhouse with honey bees had the same weight and size as those produced in one of the control greenhouses. The stingless bee, $M$. quadrifasciata, was significantly more ef-
\end{abstract}


ficient than honey bees in pollinating greenhouse tomatoes.

Key words: Greenhouse; Lycopersicon esculentum; Fruit production; Meliponini

\section{INTRODUCTION}

The tomato plant, Lycopersicon esculentum Miller, has poricidial dehiscent flowers; the anthers need to be shaken to release their pollen through apical pores (McGregor, 1976; Buchmann, 1983). In open areas, shaking by wind is usually sufficient to trigger this pollen release, promoting self-fertilization (Free, 1993). In the absence of wind, however, as is the case in greenhouses, successful pollination of cultivated tomato flowers is difficult.

Artificial mechanical vibration, using hand-held electrical shakers, is commercially employed for the pollination of tomato flowers in greenhouses. This method, however, although resulting in tomatoes of higher quality than fruits derived from self-fertilization (Banda and Paxton, 1991), is expensive and risks damaging the flowers (Banda and Paxton, 1991; Roubik, 1995). Alternatively, or in addition to such artificial vibration, bees have been used as pollinators to increase the production of greenhouse tomatoes. Traditionally, bumble bees (Apidae, Bombini) have been used for pollinating greenhouse tomatoes with great success (Plath, 1925; Banda and Paxton, 1991; Kevan et al., 1991; Asada and Ono, 1997; Dogterom et al., 1998; Estay et al., 2001; Al-Attal et al., 2003). These bees are capable of vibrating the anthers of poricidial dehiscent flowers by producing strong thoracic vibrations, which are transmitted through the bees' legs to the flowers (the so-called "buzz pollination") (Buchmann, 1983). Bumble bees, particularly Bombus terrestris, have been exported worldwide for greenhouse tomato pollination; unfortunately, such exports pose a considerable risk to the indigenous bee fauna in those countries where they are not native (Hingston and McQuillan, 1998; Goulson, 2003; Hingston, 2005). Hence, in recent years there has been an increasing interest in finding alternative, native bee species that have a pollination efficiency that is equal to or at least similar to that of bumble bees. In Australia, solitary bees that perform buzz pollination, such as Amegilla chlorocyanea and A. (Zonamegilla) holmesi (Anthophoridae), and Lestis aeratus and L. bombylans (Apidae, Xylocopinae) have been found to be very efficient in pollinating greenhouse tomatoes (Hogendoorn et al., 2000, 2006; Bell et al., 2006). In Latin America, stingless bees (Apidae, Meliponini) have received increasing attention as crop pollinators during the past few years. These highly eusocial bees live in perennial colonies, are easily domesticated and show various behavioral traits (such as recruitment of foragers (Lindauer and Kerr, 1960), high flower constancy, great diet-breadth, and easy adaptation to new plant species) that make them promising candidates as pollinators of commercial crops (Roubik et al., 1986; Ramalho et al., 1994; Nogueira-Neto, 1997; Heard, 1999).

Until now, studies on the production of greenhouse tomatoes have concentrated on the pollination efficiency of a single bee species. However, it would be useful to compare bee species. We investigated and compared the efficiency of two eusocial bee species that have been reported to be successful pollinators of crops. We used the most common commercial crop pollinator, the honey bee Apis mellifera (Sabara and Winston, 2003; Higo et al., 2004). This bee was compared with a native stingless bee, Melipona quadrifasciata (Del Sarto et al., 2005); M. quadrifasciata, is a species of Neotropical stingless bees (Meliponini) that is well adapted to the subtropical climate of the Ribeirão Preto region. Furthermore, these bees are easy to handle and have a docile behavior. Nests of 
M. quadrifasciata can be found from the northeast to the south of Brazil (Nogueira-Neto, 1997). The honey bee, A. mellifera, is commonly used for the pollination of commercial crops. This is due to the large number of individuals per colony, as well as to the continuous brood-provisioning process, which demands a constant collection of floral resources, such as nectar and pollen (Barth, 1991). We examined whether tomato quantity and quality differs when pollinated by these two bee species.

\section{MATERIALAND METHODS}

The pollination experiment was conducted in four greenhouses as well as in an external open plot (measuring $87.5 \mathrm{~m}^{2}$ each) on the campus of the University of São Paulo in Ribeirão Preto, Brazil, from October to December 2002. The greenhouses had a transparent plastic roof and were laterally covered with a dark plastic screen that decreased the luminosity by $30 \%$.

One hundred and twenty tomato plants were transplanted into each plot (four greenhouses and one open area). In all cases, the plants were arranged in six rows of 20 plants each, with a onemeter-wide aisle between the rows. Three colonies ( $\approx 500$ bees per colony) of $M$. quadrifasciata were introduced into greenhouse $\mathrm{A}$, and one colony of A. mellifera $(\approx 10,000$ bees $)$ was introduced into greenhouse B. Greenhouses $\mathrm{C}$ and $\mathrm{D}$ had no bee colonies and served as controls. The open field plot was exposed to outside insect visitors. We collected the tomato-plant visiting insects between 6:00 and 18:00 h, during $15 \mathrm{~min}$ each hour in the open area. The captured insects were placed in glass vials, for later identification.

Counts were made of the number of tomatoes produced in each plot. Fruit characteristics were measured for 200 fruits from each plot, as soon as they were yellow-red in color. The tomatoes were weighed to the nearest gram, their vertical and transverse circumferences were measured to the nearest centimeter, and the seeds in each fruit were counted. We compared these parameters with one-way ANOVA; the Kruskal-Wallis test was used when the criteria for parametric analysis were not met. Post hoc pairwise comparisons, the Tukey test (used with one-way ANOVA) or the Dunn test (used with the Kruskal-Wallis test), specified which samples differed. The level for significance of difference was established as $\mathrm{P} \leq 0.05$. The statistical analyses were made using the SigmaStat 3.1 software.

\section{RESULTS AND DISCUSSION}

In the open plot, we collected 253 flower beetles (Chrysomelidae), 17 sweat bees (Halictidae), one stingless bee (Paratrigona sp), and one honey bee (A. mellifera).

\section{Fruit production}

The largest number of fruits (1414 tomatoes) was harvested from the greenhouse with $M$. quadrifasciata. The smallest number of fruits was produced in the open area (730 tomatoes). The greenhouse with honey bees produced 1220 tomatoes, similar to what was produced in the two control greenhouses (no bees) (1220 in greenhouse C and 1187 in greenhouse D).

\section{Fruit weight, circumference (vertical and transversal) and seed counts}

The heaviest tomatoes were produced in the greenhouse with the stingless bee M. quadri- 
fasciata (Figure 1A). The tomatoes from this greenhouse were significantly heavier than those produced in all the other plots ( $\mathrm{P} \leq 0.05$, Kruskal-Wallis test; $\mathrm{P} \leq 0.05$, Dunn comparison). The tomatoes produced in the greenhouse with honey bees did not significantly differ in weight from those produced in one of the control greenhouses ( $\mathrm{P}>0.05$, Dunn comparison). However, tomatoes from these two greenhouses were significantly heavier than those produced in the other greenhouse $\mathrm{D}$, and those produced in the open plot ( $\mathrm{P} \leq 0.05$, Dunn comparison). The differences between plots were also found for fruit circumference (Figure 1B and C) and seed count (Figure 1D). We concluded that the stingless bee M. quadrifasciata is significantly more efficient in pollinating greenhouse tomatoes than is the honey bee. Along with increased fruit set, the tomatoes pollinated by $M$. quadrifasciata were larger and had more seeds than those produced with honey bees in the greenhouse, in greenhouses without pollinators and in the open field plot (Figure 1).

Several recent studies have also shown that Melipona spp are efficient pollinators of economically important crops, including sweet pepper (Cruz et al., 2005) and tomatoes (Del Sarto et al., 2005). These bees easily adapt to greenhouses (Cruz et al., 2004; Del Sarto et al., 2005), and there are well-established techniques for multiplying the colonies (Nogueira-Neto, 1997), further increasing the potential economic value of these bees as crop pollinators.

We found that greenhouse tomatoes pollinated by M. quadrifasciata had greater fruit set and higher fruit quality than those without pollination, as also reported by Del Sarto et al. (2005). However, in that study, the control flowers were bagged, resulting in complete failure of fruit set. In our study, however, self-fertilization (most probably through wind pollination) occurred in all three control plots (the two greenhouses and the open plot). Apparently, our control plots were closer to a normal commercial production situation than in the study conducted by Del Sarto et al. (2005).

Honey bees (A. mellifera) are often used as pollinators of crops in order to increase or improve production, such as in arrowleaf clover (Trifolium vesiculosum) seed production (Camacho et al., 1999). Though these bees do not efficiently vibrate greenhouse tomato flowers, some benefit from honey bee pollination has been reported (Banda and Paxton, 1991; Sabara and Winston, 2003; Higo et al., 2004). We found a small beneficial effect when compared to one of the two control greenhouses and the open plot (Figure 1). The other control greenhouse had similar fruit quality to the production in the greenhouse with honey bees. Unfortunately, we could not find a reason for the differences between the two control greenhouses.

The tomato flowers in the open plot were potentially exposed to honey bees and many species of solitary bees and social stingless bees. Nevertheless, fruit quality (weight, seed number and size) in this plot was similar to that in greenhouse D, which had no bee/insect visitors. This could be due to the fact that the nectar secretion of tomato flowers is of little, if any, value for bee visitors (McGregor, 1976). Furthermore, not all insects are capable of vibrating flowers. Most efficient pollinators of greenhouse tomatoes are buzz-pollinators $[M$. quadrifasciata: Del Sarto et al., 2005; Bombus terrestris: Kevan et al., 1991; Banda and Paxton, 1991; Pressman et al., 1999; B. hypocrite hypocrite and ignutos: Asada and Ono, 1997; B. vosnesenskii: Dogterom et al., 1998; B. dahlbomii: Estay et al., 2001; Amegilla (Zonamegilla) holmesi: Bell et al., 2006; Amegilla chlorocyanea and Xylocopa (Lestis) aeratus: Hogendoorn et al., 2000, 2006]. The fact that $A$. mellifera is not capable of performing buzz-pollination would explain the finding that these bees are less efficient pollinators of greenhouse tomatoes than are Melipona bees or bumble bees (M. quadrifasciata: present study; B. terrestris: Banda and Paxton, 1991). 


$$
\text { A }
$$
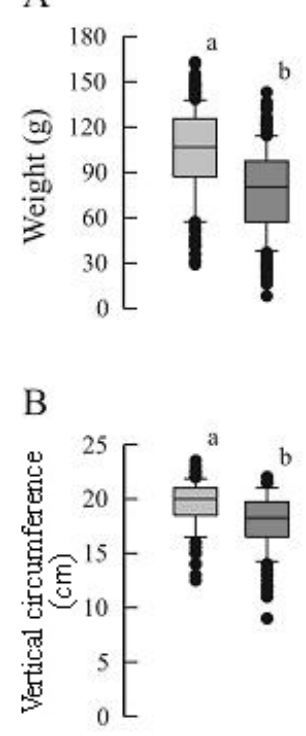

$\mathrm{H}=263.6, \mathrm{P}<0,001$

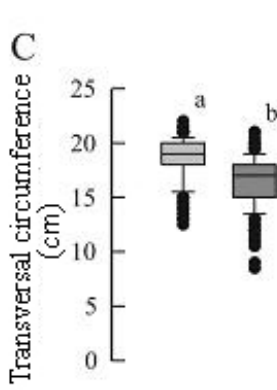

$\mathrm{D}$
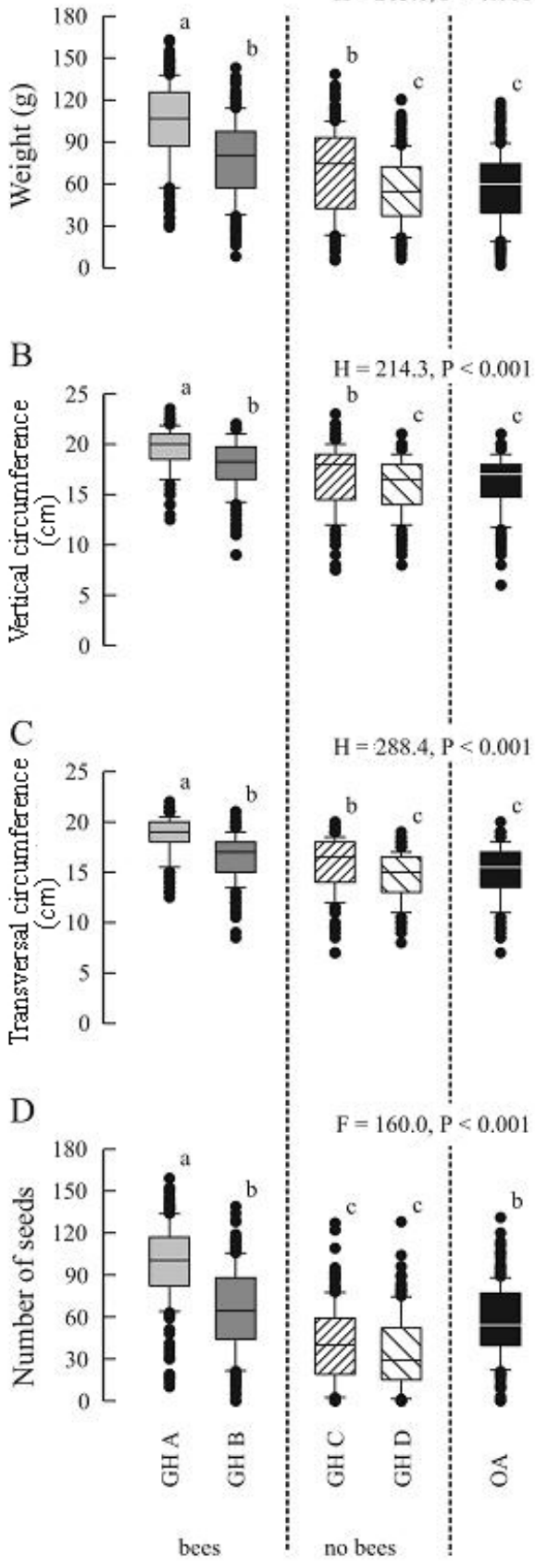

$\mathrm{H}=288.4, \mathrm{P}<0.001$

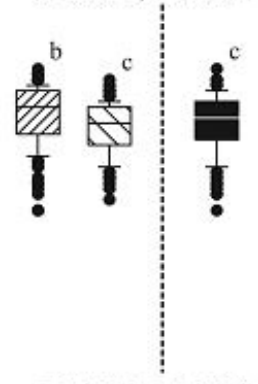

$\mathrm{F}=160.0, \mathrm{P}<0.001$

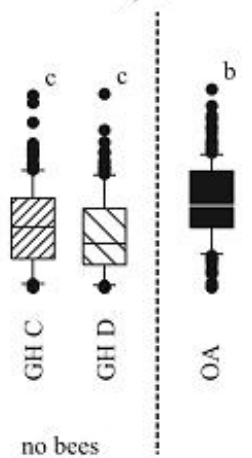

Figure 1. Comparisons between weight, vertical and transversal circumferences and number of seeds of tomato fruits in plots with and without bees. Different letters $(a, b, c)$ denote statistical differences at $\mathrm{P} \leq 0.05$. GH A $=$ greenhouse A, which contained three colonies of Melipona quadrifasciata; GH B contained one colony of Apis mellifera; GH C and GH D were control greenhouses, without bees; $\mathrm{OA}=$ open field plot, exposed to insect visitors. 
We conclude that native stingless bees can be used in Brazil to increase the quantity and quality of production of commercial greenhouse tomatoes and that M. quadrifasciata is a more efficient pollinator of greenhouse tomatoes than is A. mellifera.

\section{ACKNOWLEDGMENTS}

We are grateful to FAPESP, CAPES and CNPq for financial support.

\section{REFERENCES}

Al-Attal YZ, Kasrawi MA and Nazer IK (2003). Influence of pollination technique on greenhouse tomato production. Agric. Mar. Sci. 8: 21-26.

Asada S and Ono M (1997). Tomato pollination with Japanese native bumblebees (Bombus spp.). Acta Hotic. 437: $289-292$.

Banda HJ and Paxton RJ (1991). Pollination of greenhouse tomatoes by bees. Acta Hortic. 288: 194-198.

Barth FG (1991). Insects and Flowers - The Biology of a Partnership. Princeton University Press, New Jersey.

Bell MC, Spooner-Hart RN and Haigh AM (2006). Pollination of greenhouse tomatoes by the Australian bluebanded bee Amegilla (Zonamegilla) holmesi (Hymenoptera: Apidae). J. Econ. Entomol. 99: 437-442.

Buchmann SL (1983). Buzz Pollination in Angiosperms. In: Handbook of Experimental Pollination Biology (Jones CE and Little RJ, eds.). Van Nostrand Reinhold, New York, 73-113.

Camacho JCB, Monks PL and Silva JB (1999). A polinização entomófila na produção e qualidade germinativa de sementes de trevo vesiculoso (Trifolium vesiculosum Savi) cv. Embrapa-28 "Santa Tecla". [Entomophilous pollination and its effect on arrowleaf clover (Trifolium vesiculosum Savi) cv. Embrapa-28 "Santa Tecla"]. Rev. Bras. Agrocienc. 5: 114-119.

Cruz DO, Freitas BM, Silva LA, Silva EMS, et al. (2004). Adaptação e comportamento de pastejo da abelha jandaíra (Melipona subnitida Ducke) em ambiente protegido. [Adaptation and foraging behavior of the stingless bee (Melipona subnitida) Ducke in a caged environment]. Acta Scientiarum Anim. Sci. 26: 293-298.

Cruz DO, Freitas BM, Silva LA, Silva EMS, et al. (2005). Pollination efficiency of the stingless bee Melipona subnitida on greenhouse sweet pepper. Pesq. Agropec. Bras. 40: 1197-1201.

Del Sarto MC, Peruquetti RC and Campos LA (2005). Evaluation of the Neotropical stingless bee Melipona quadrifasciata (Hymenoptera: Apidae) as pollinator of greenhouse tomatoes. J. Econ. Entomol. 98: 260-266.

Dogterom MH, Matteoni JA and Plowright RC (1998). Pollination of greenhouse tomatoes by the North American Bombus vosnesenskii (Hymenoptera: Apidae). J. Econ. Entomol. 91: 71-75.

Estay P, Wagner A and Escaff M (2001). Evaluación de Bombus dahlbomii (Guér.) como agente de flores de tomate (Lycopersicon esculentum (Mill), bajo condiciones de invernadero. [Evaluation of Bombus dahlbomii (Guér.) as a pollinating agent for tomato (Lycopersicon esculentum (Mill.)) flowers under greenhouse conditions]. Agric. Tec. 61: 113-119.

Free JB (1993). Insect Pollination of Crops. 2nd edn. Academic Press, London.

Goulson D (2003). Effects of introduced bees on native ecosystems. Annu. Rev. Ecol. Evol. Syst. 34: 1-26.

Heard TA (1999). The role of stingless bees in crop pollination. Annu. Rev. Entomol. 44: 183-206.

Higo HA, Rice ND, Winston ML and Lewis B (2004). Honey bee (Hymenoptera: Apidae) distribution and potential for supplementary pollination in commercial tomato greenhouses during winter. J. Econ. Entomol. 97: 163-170.

Hingston AB (2005). Does the introduced bumblebee, Bombus terrestris (Apidae), prefer flowers of introduced or native plants in Australia? Austr. J. Zool. 53: 29-34.

Hingston AB and McQuillan PB (1998). Does the recently introduced bumblebee Bombus terrestris (Apidae) threaten Australian ecosystems? Austr. J. Ecol. 23: 539-549.

Hogendoorn K, Steen Z and Schwarz MP (2000). Native Australian carpenter bees as a potential alternative to introducing bumble bees for tomato pollination in greenhouses. J. Apic. Res. 39: 67-74.

Hogendoorn K, Gross CL, Sedgley M and Keller MA (2006). Increased tomato yield through pollination by native Australian Amegilla chlorocyanea (Hymenoptera: Anthophoridae). J. Econ. Entomol. 99: 828-833.

Kevan PG, Straver WA, Offer M and Laverty M (1991). Pollination of greenhouse tomatoes by bumble bees in Ontario. Proc. Entomol. Soc. Ont. 122: 15-19.

Lindauer M and Kerr WE (1960). Communication between the workers of stingless bees. Bee World 41: 65-71.

McGregor SE (1976). Insect Pollination of Cultivated Crop Plants. Agricultural Research Service, Washington.

Nogueira-Neto P (1997). Vida e Criação de Abelha sem Ferrão. Editora Nogueirapis, São Paulo.

Plath OE (1925). The role of bumblebees in the pollination of certain cultivated plants. Am. Nat. 59: 441-451. 
Pressman E, Shaked R, Rosenfeld K and Hefetz A (1999). A comparative study of the efficiency of bumble bees and an electric bee in pollinating unheated greenhouse tomatoes. J. Hortic. Sci. Biotechnol. 74: 101-104.

Ramalho M, Giannini TC, Malagodi-Braga KS and Imperatriz-Fonseca VL (1994). Pollen harvest by stingless bee foragers (Hymenoptera, Apidae, Meliponinae). Grana 33: 239-244.

Roubik DW (1995). Pollination of Cultivated Plants in the Tropics: Food and Agriculture Organization, Rome, Italy. Agric. Serv. Bull. 118.

Roubik DW, Moreno JE, Vergara C and Wittmann D (1986). Sporadic food competition with the African honey bee: projected impact on Neotropical social bees. J. Trop. Ecol. 2: 97-111.

Sabara HA and Winston ML (2003). Managing honey bees (Hymenoptera: Apidae) for greenhouse tomato pollination. $J$. Econ. Entomol. 96: 547-554. 